\title{
Surto de compactação primária de abomaso em bovinos leiteiros associado ao consumo de silagem de girassol ${ }^{1}$
}

\author{
Leonardo P. Mesquita², Camila C. Abreu², Clayton I. Nogueira², Saulo P. Pavarini ${ }^{3}$, Josilene \\ N. Seixas ${ }^{2}$, Mary S. Varaschin ${ }^{2}$, Pedro S. Bezerra Júnior ${ }^{2}$ e Flademir Wouters ${ }^{2^{*}}$
}

\begin{abstract}
Mesquita L.P., Abreu C.C., Nogueira C.I., Pavarini S.P., Seixas J.N., Varaschin M.S., Bezerra Jr P.S. \& Wouters F. 2012. [Outbreak of primary abomasal impaction in dairy cattle associated with consumption of sunflower silage.] Surto de compactação primária de abomaso em bovinos leiteiros associado ao consumo de silagem de girassol. Pesquisa Veterinária Brasileira 32(6):510-514. Setor de Patologia Veterinária, Departamento de Medicina Veterinária, Universidade Federal de Lavras, Campus Universitário, Cx. Postal 3037, Lavras, MG 37200-000, Brazil. E-mail: flademir@dmv.ufla.br

An outbreak of primary abomasal impaction associated with consumption of sunflower silage occurred in a dairy cattle herd from the state of Minas Gerais. Six of 21 dry cows in late pregnancy fed with sunflower silage died. Cattle that became ill presented abdominal distension and scant and dried feces. In the animals that died, severe dehydration, pale mucous membranes, dark, sticky and stinking feces were seen. Three cows were necropsied and the main pathological findings consisted of severe abomasal distension associated with a large quantity of dried alimentary content covered by bloody clots. Ulcers were found in abomasum, with perforation in one cow. Feeding cattle with high nutritional needs, with sunflower silage of undesirable characteristics as unique source of roughage was the main cause for the abomasal impaction.
\end{abstract}

INDEX TERMS: Cattle, abomasal impaction, abomasal ulcer, sunflower silage.

RESUMO.- Um surto de compactação primária de abomaso associada ao consumo de silagem de girassol ocorreu num rebanho bovino leiteiro do estado de Minas Gerais, do qual seis de 21 vacas secas em fase final de gestação e que recebiam silagem de girassol morreram. Os bovinos que adoeceram apresentaram distensão abdominal, fezes ressecadas e escassas e, nos bovinos que morreram, eram pastosas, escuras e fétidas; nesses havia também desidratação acentuada e palidez de mucosas. Três bovinos foram necropsiados e os achados patológicos eram constituídos principalmente por distensão acentuada do abomaso associada a grande quantidade de conteúdo alimentar ressecado coberto por coágulos de sangue. No abomaso havia úlceras, com perfuração da parede em um dos bovinos. A

\footnotetext{
1 Recebido em 28 de setembro de 2011.

Aceito para publicação em 17 de fevereiro de 2012.

2 Setor de Patologia Veterinária, Departamento de Medicina Veterinária, Universidade Federal de Lavras (UFLA), Campus Universitário, Caixa Postal 3037, Lavras, MG 37200-000, Brasil. *Autor para correspondência: flademir@dmv.ufla.br

3 Departamento de Patologia Clínica Veterinária, Faculdade de Veterinária, Universidade Federal do Rio Grande do Sul (UFRGS), Av. Bento Gonçalves 9090, Porto Alegre, RS 95320-000, Brasil.
}

alimentação de bovinos de maior exigência nutricional com silagem de girassol de características indesejáveis como única fonte de volumoso foi o principal fator para a compactação de abomaso nos casos apresentados.

TERMOS DE INDEXAÇÃO: Bovinos, compactação de abomaso, úlceras de abomaso, silagem de girassol.

\section{INTRODUÇÃo}

A compactação de abomaso pode ser definida como um acúmulo de ingesta no órgão com falha na progressão da mesma (Guard 2006) e pode ser primária ou secundária. A compactação secundária pode ser decorrente de estase abomasal em casos de indigestão vagal ou doença sistêmica que possa cursar com estase (Merritt \& Boucher 1967, Brown et al. 2007). Indigestão vagal pode ocorrer por lesões inflamatórias intratorácicas, por envolvimento do nervo vago em aderências secundárias como em casos de reticuloperitonite traumática, lesão vagal por correção cirúrgica de deslocamento de abomaso e lesões vagais decorrentes de infiltração neoplásica (Brown et al. 2007).

A compactação abomasal primária pode ser causada pela ingestão de forragens de baixa qualidade, associada 
ou não à restrição hídrica (Moscardini \& Borges 2007). Há relatos de compactação primária em bovinos associada à ingestão de areia (Melendez et al. 2007), palha de culturas (Ashcroft 1983), casca de amêndoas (Mitchell 1991), caule de ervilha (Simkins \& Nagele 1997), e de capim-elefante (Pennisetum purpureum) em estado avançado de maturação e com concentrações elevadas de lignina (Borges et al. 2007). No Brasil, a principal causa é a ingestão de forrageiras trituradas e ricas em lignina, seguida pela ingestão de cama de frango e palha de arroz (Moscardini \& Borges 2007). Em países de clima temperado a ocorrência da enfermidade no inverno provavelmente está associada à ingestão de alimentos fibrosos e secos (Ashcroft 1983). Em estudo prévio no Brasil, de 14 casos da enfermidade, $71,4 \%$ ocorreram na estação da seca (Câmara et al. 2009). Acredita-se que bovinos em adiantado estado de gestação sejam mais suscetíveis, em decorrência do aumento das exigências alimentares (Simkins \& Nagele 1997). A compactação de abomaso é pouco documentada no Brasil, o que pode estar relacionado à dificuldade no diagnóstico clínico (Borges et al. 2007, Câmara et al. 2009).

Este trabalho tem como objetivo relatar a ocorrência e descrever os achados clinicopatológicos de um surto de compactação primária de abomaso em um rebanho bovino no Sul de Minas Gerais, sendo o primeiro associado ao consumo de silagem de girassol.

\section{MATERIAL E MÉTODOS}

Em visitas à propriedade foram realizados exames clínicos e necropsias de bovinos afetados, bem como coleta de dados epidemiológicos junto a proprietário e funcionários. Fragmentos de órgãos foram colhidos na necropsia de três bovinos, fixados em solução de formalina $10 \%$ tamponada, desidratados em concentrações crescentes de álcool etílico, diafanizados em xilol e incluídos em parafina, efetuados cortes de $5 \mu \mathrm{m}$ de espessura, corados por hematoxilina e eosina (HE) e avaliados.

\section{RESULTADOS}

A compactação de abomaso ocorreu numa propriedade rural destinada à produção de leite no município de $\mathrm{Ne}$ pomuceno, Minas Gerais, Brasil. O rebanho era composto principalmente por bovinos da raça Holandesa e um lote do rebanho era formado originalmente por 21 vacas de três a cinco anos de idade, não lactantes (vacas secas), em terço final de gestação e com data do parto próxima. Em outubro de 2005 todos os animais do referido lote apresentaram quadro clínico, de intensidade variada, caracterizado por apatia, mucosas pálidas, desidratação acentuada, abdômen distendido, fezes ressecadas e escassas que, em alguns bovinos, tornaram-se pastosas e escurecidas, lembrando piche (Fig.1). Num dos animais houve antecipação do parto em três dias, com parição de um natimorto. Cada vaca recebia aproximadamente $25 \mathrm{~kg} /$ dia de silagem de girassol (planta inteira), sem outros componentes na dieta. 0 cultivar de girassol utilizado foi o IAC Uruguai, de ciclo tardio e indicado para produção de óleo. A colheita foi realizada 147 dias após o plantio, realizado no final de março de 2005. Na colheita as plantas apresentavam folhas totalmente secas; capítulos e caules acastanhados e secos e $100 \%$ dos grãos estavam

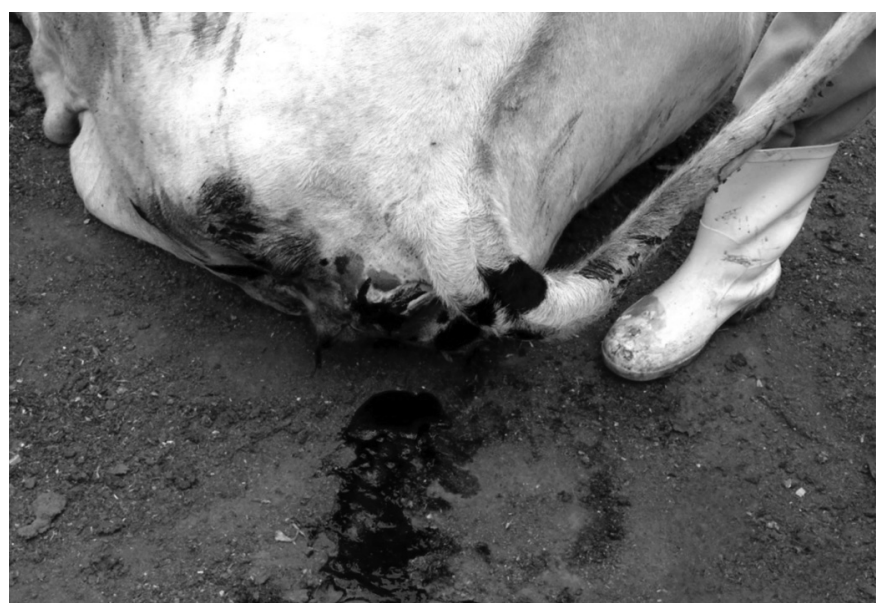

Fig.1. Surto de compactação de abomaso em bovinos leiteiros associado ao consumo de silagem de girassol. Fezes pastosas e escuras, com aspecto de piche (Bovino 3).

maduros. A ensiladeira havia sido regulada para o corte de partículas com média de $3 \mathrm{~cm}$ de comprimento, no entanto, como a planta estava seca o corte na ensiladeira não foi eficiente, formando partículas de 5 a $8 \mathrm{~cm}$, fibrosas e ásperas. A silagem passou a ser fornecida aos bovinos 21 dias após confeccionada e os sinais clínicos começaram sete dias após início do fornecimento da silagem. Nas seis vacas que morreram o curso clínico da doença variou de oito a 16 dias. Após a última morte foi suspenso o fornecimento da silagem, com recuperação clínica dos demais animais do lote. As vacas em lactação recebiam aproximadamente $1 \mathrm{~kg} /$ dia da silagem de girassol; nenhuma delas manifestou doença clínica.

Dos seis bovinos que morreram, três foram necropsiados (Bovinos 1, 2 e 3). As alterações macroscópicas observadas durante a necropsia foram similares nos três casos e caracterizadas por regular estado corporal, mucosas pálidas, desidratação acentuada, evidenciada por retração acentuada dos globos oculares; abomaso acentuadamente distendido ocupando grande área da porção cranial direita do abdômen (Fig.2), repleto de conteúdo alimentar ressecado, compactado e fibroso (Fig.3); coágulos de sangue e muco envolviam a superfície da massa compactada. Na região do corpo abomasal havia úlceras de aproximadamente $2 \mathrm{~cm}$ de diâmetro e superfície enegrecida. Na serosa do abomaso do Bovino 1 havia grande quantidade de fibrina entremeada por conteúdo abomasal, principalmente nas proximidades da úlcera abomasal perfurada. No intestino delgado havia conteúdo liquefeito, escuro e fétido e, no intestino grosso, conteúdo pastoso enegrecido. 0 fígado estava difusamente amarelado (Fig.2). No Bovino 2 havia também grande quantidade de conteúdo fibroso e de partículas grosseiras no omaso. Nos pulmões do Bovino 3 havia aderências fibrosas entre pleura parietal e visceral e, na região cranioventral, áreas de bronquiectasia associadas a conteúdo catarropurulento.

Os principais achados histopatológicos incluíram ulceração da mucosa abomasal com grande quantidade de material necrótico, colônias bacterianas e neutrófilos degenerados na mucosa, além de inúmeras fibras vegetais. $\mathrm{Na}$ submucosa observaram-se infiltrado acentuado de macrófagos e neutrófilos e ocasionais linfócitos em meio a tecido de 


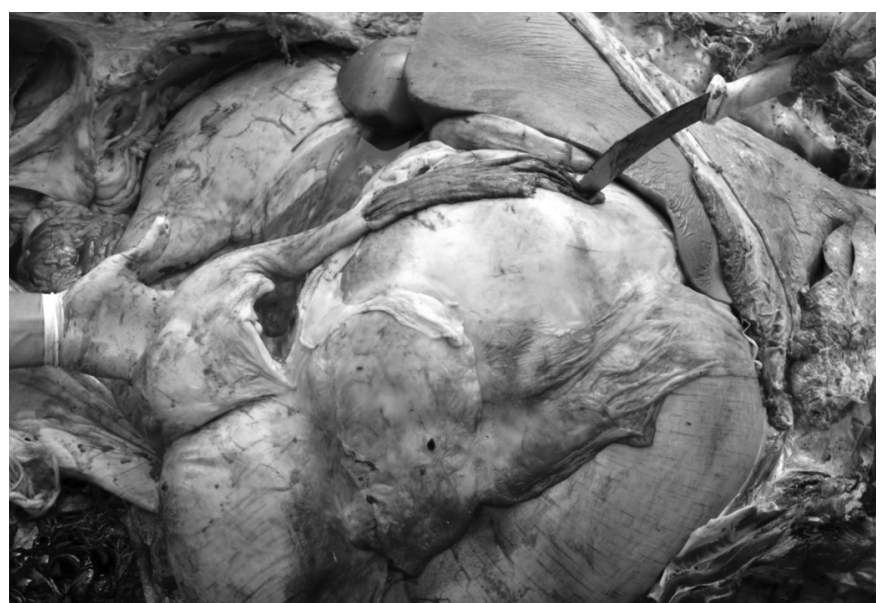

Fig.2. Surto de compactação de abomaso em bovinos leiteiros associado ao consumo de silagem de girassol. Distensão acentuada de abomaso e omaso, e fígado amarelado (Bovino 2).

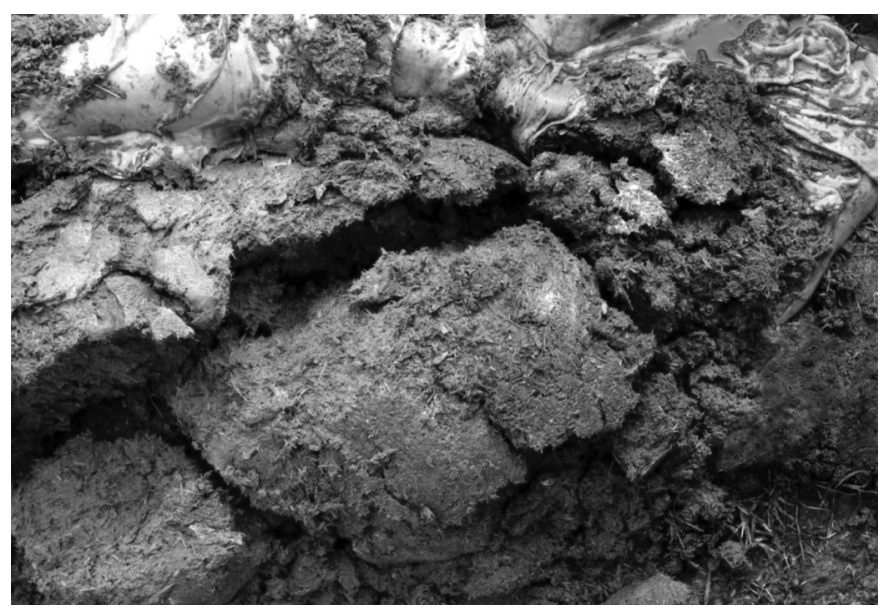

Fig.3. Surto de compactação de abomaso em bovinos leiteiros associado ao consumo de silagem de girassol. Grande quantidade de conteúdo abomasal seco e compactado (Bovino 2).

granulação, que se estendia até as camadas mais externas da musculatura lisa da parede abomasal. No Bovino 1, no qual a ulceração abomasal era transmural, havia infiltrado inflamatório também na serosa. No fígado de todos os bovinos havia esteatose e congestão difusas, moderadas e, adicionalmente, no Bovino 1 havia trombos em veias centrolobulares e do espaço porta. No intestino delgado do Bovino 2 havia depleção linfoide moderada nas placas de Peyer, com herniação de criptas intestinais, substituindo parcialmente os folículos linfoides. Algumas criptas estavam revestidas por células epiteliais achatadas, com material necrótico no lúmen. Nos pulmões do Bovino 3 visualizaram-se pneumonia broncointersticial acentuada, fibrose intersticial extensa associada a proliferação de pneumócitos tipo II, bronquiolite necrosante com formação de sincícios celulares, principalmente no interior de alvéolos e bronquíolos e ocasionais neutrófilos no interior de bronquíolos.

\section{DISCUSSÃO E CONCLUSÕES}

O diagnóstico de compactação de abomaso baseou-se na epidemiologia, nas manifestações clínicas e, principalmen- te, nos achados de necropsia, semelhantes aos descritos em outros estudos (Merritt \& Boucher 1967, Ashcroft 1983, Mitchell 1991, Simkins \& Nagele 1997, Wittek et al. 2005, Borges et al. 2007, Melendez et al. 2007, Moscardini \& Borges 2007). A quantidade de silagem consumida, as condições da mesma e da planta no período de preparo muito provavelmente favoreceram o surto.

$\mathrm{Na}$ confecção de silagem de girassol é especialmente importante a atenção para o ponto correto de colheita da planta, devendo ser considerada a idade da planta, avaliadas características tais como o estágio de desenvolvimento do girassol, a cultivar e as condições de cultivo, além de características morfológicas da planta (Evangelista \& Lima 2001). No presente estudo, o girassol IAC Uruguai, caracteristicamente de ciclo tardio, havia sido colhido 147 dias após o plantio, prazo bem acima do recomendado, uma vez que a duração do ciclo de produção de girassol para ensilagem é de aproximadamente 130 dias para os cultivares tardios (Evangelista \& Lima 2001). Em estudo com quatro genótipos de girassol, ensilados em diferentes idades de corte, observou-se diminuição dos valores de digestibilidade in vitro nos estágios mais avançados de maturação (Souza et al. 2005), declínio este relacionado com o aumento de carboidratos estruturais decorrente do avanço na idade da planta (McDonald et al. 1991). O cultivar IAC Uruguai, ensilado quando tinha $100 \%$ dos grãos maduros, apresentou maiores teores de matéria seca (MS) e celulose e menor conteúdo protéico em comparação com outros cultivares, indicando um estado de maturação avançado (Jayme et al. 2007). Dados apresentam menor taxa de digestibilidade in vitro para a silagem confeccionada com o genótipo IAC Uruguai, classificada como de média qualidade quanto à digestibilidade (Jayme et al. 2007). Morfologicamente, o ponto ideal de corte, quando há características fermentativas e nutricionais satisfatórias, é na fase reprodutiva R9 (Tomich et al. 2004b), caracterizada por amarelamento da parte posterior dos capítulos, brácteas (folhas na parte externa do capítulo) amarelo-acastanhadas e maior parte das folhas presas ao caule já secas (Castiglioni et al. 1997). A avaliação da planta no momento do corte é importante, pois o girassol apresenta teor de umidade elevado, desfavorável ao processo fermentativo, por isso é colhida no estágio de maturação fisiológica, quando há mais de $90 \%$ de grãos maduros (Evangelista \& Lima 2001). Entretanto, as plantas de girassol do presente estudo encontravam-se acentuadamente secas, com $100 \%$ de grãos maduros, todas as folhas já estavam ressecadas e as brácteas castanho-escuras, sugerindo que o estado ideal de maturação já havia passado. As características morfológicas do girassol prejudicaram o processo de confecção da silagem, uma vez que dificultou a passagem das plantas pela ensiladeira com formação de partículas entre 5 e $8 \mathrm{~cm}$ de comprimento. Nas silagens de girassol geralmente se recomendam partículas com tamanho de 1 a $2 \mathrm{~cm}$ (Tomich et al. 2003, Mello et al. 2004, Tomich et al. 2004a, Souza et al. 2005, Mello et al. 2006, Jayme et al. 2007). Partículas excessivamente grandes, como as observadas na silagem usada na propriedade do presente surto, podem diminuir a taxa de passagem e reduzir o consumo de MS, o que ocorre principalmente 
em forragens com baixa digestibilidade da fração fibrosa (Saenz 2005). 0 tamanho das partículas, portanto, torna-se especialmente importante quando se trata da silagem de girassol, uma vez que conteúdos de lignina elevados têm sido encontrados em silagens de girassol de diferentes cultivares (Tomich et al. 2004b, Possenti et al. 2005). A ingestão de forragens de baixa qualidade e ricas em lignina é uma das principais causas da compactação de abomaso em bovinos (Moscardini \& Borges 2007), observada também na utilização de capim-elefante em estado avançado de maturação e com elevada concentração de lignina (Borges et al. 2007, Câmara et al. 2009).

No presente trabalho, as vacas secas recebiam exclusivamente silagem de girassol, aproximadamente $25 \mathrm{~kg} / \mathrm{dia} /$ animal. No entanto, não foi possível contabilizar o consumo exato de nutrientes, uma vez que não foi realizada análise bromatológica da silagem, assim como a contabilização das sobras. As vacas em lactação, que consumiam apenas $1 \mathrm{~kg} /$ dia em média dessa silagem, não desenvolveram a enfermidade. Avaliações de consumo e desempenho de bovinos alimentados com silagem de girassol, além do valor nutritivo e de digestibilidade, são fundamentais para verificar a qualidade da mesma (Evangelista \& Lima 2001).

Os três bovinos necropsiados estavam em estado avançado de gestação. 0 terço final de gestação é considerado condição favorável para a ocorrência da doença, relacionada ao aumento das exigências nutricionais (Moscardini \& Borges 2007). Somente essa categoria animal estava recebendo a silagem em maior quantidade. No entanto, como observado por outro autor (Ashcroft 1983), o estado gestacional, embora provavelmente tenha contribuído, não foi o fator decisivo para a doença nos casos apresentados.

Os sinais clínicos de apatia, desidratação, distensão abdominal, fezes ressecadas e escassas, apresentados pelos bovinos do presente estudo, são frequentes em casos de compactação abomasal (Baker 1979, Mitchell 1991, Simkins \& Nagele 1997, Wittek et al. 2005, Guard 2006, Borges et al. 2007, Melendez et al. 2007, Câmara et al. 2009). Podem ocorrer também diminuição ou ausência da motilidade ruminal; estrutura compactada palpável no abdômen ventral direito (Radostits et al. 2007, Câmara et al. 2009) e aumento da frequência respiratória resultante de compressão torácica por aumento de volume abdominal (Radostits et al. 2007). O exame de palpação retal pode auxiliar no diagnóstico clínico embora, em alguns casos, o abomaso não seja palpável (Borges et al. 2007). A aferição do teor de cloretos no fluido ruminal pode auxiliar o diagnóstico clínico de compactação de abomaso (Câmara et al. 2009). A elevação no teor de cloretos se deve ao refluxo da ingesta abomasal rica em ácido clorídrico para os proventrículos, culminando em alcalose metabólica, hipocloremia e hipocalemia sistêmicas (Guard 2006, Radostits et al. 2007).

As fezes escuras observadas nos bovinos que morreram indicam sangramento nas porções mais craniais do trato gastrintestinal, como úlceras abomasais hemorrágicas, e que o sangue foi submetido a processos digestivos. (Radostits et al. 2007, Gelberg 2009). Em todos os bovinos necropsiados havia úlceras no corpo abomasal e, num deles, perfuração da parede abomasal e peritonite fibrinosa aguda localizada. Há relato de bovinos com compactação de abomaso e que apresentaram fezes com sangue (Ashcroft 1983), no entanto, nem todos os animais com úlceras apresentam esse sinal clínico. Uma vez que os sinais clínicos são inespecíficos e variáveis, a laparotomia exploratória no flanco direito pode auxiliar para um correto diagnóstico clínico (Wittek et al. 2005).

A ocorrência de úlceras associadas à compactação está relacionada à injúria inicial, com passagem de íons hidrogênio para a mucosa, permitindo também a ação da pepsina em várias camadas da parede abomasal, causando dano maior (Radostits et al. 2007). Úlceras primárias associadas a peritonite localizada podem interferir na motilidade, com prejuízo no esvaziamento do abomaso (Borges et al. 2007) e contribuem para o agravamento da doença. Nos presentes casos, as úlceras provavelmente estavam relacionadas à injúria provocada pela massa compactada e fibrosa que distendia a parede abomasal. Os animais apresentavam fígado difusamente amarelado que, na microscopia, correspondia a degeneração gordurosa difusa moderada. Esta condição foi associada ao aumento na mobilização de gordura dos depósitos corporais (Gelberg 2009).

No diagnóstico diferencial devem ser consideradas compactação secundária à indigestão vagal, peritonite, obstrução intestinal e compactação de omaso (Radostits et al. 2007). Úlceras abomasais primárias ou secundárias como as associadas às neoplasias, como exemplo a leucose enzoótica bovina, devem também ser consideradas no diagnóstico diferencial, pois clinicamente são caracterizadas por melena (Brown et al. 2007). Todos os bovinos necropsiados no presente estudo apresentaram melena.

Manejo alimentar correto, com suplementação adequada para os animais com maiores exigências nutricionais, como bovinos em terço final de gestação, são fatores essenciais para a prevenção da compactação primária de abomaso (Moscardini \& Borges 2007).

No presente estudo, o uso de silagem de girassol com características indesejáveis e seu fornecimento como única fonte de volumoso favoreceu a ocorrência da compactação de abomaso. No entanto, a silagem de girassol pode ser considerada uma boa opção para a alimentação de bovinos, desde que sejam empregadas cultivares apropriadas para o ensilamento, com corte das plantas em idade e aspecto morfológico adequados, obtenção de partículas de 1 a $2 \mathrm{~cm}$ de comprimento e fornecimento da silagem em proporções adequadas na dieta.

Agradecimentos.- À Coordenação de Aperfeiçoamento de Pessoal de Nível Superior (CAPES), pela concessão de bolsas.

\section{REFERÊNCIAS}

Ashcroft R.A. 1983. Abomasal impaction of cattle in Saskatchewan. Can. Vet. J. 24:375-380.

Baker J.S. 1979. Abomasal impaction and related obstruction of the forestomachs in cattle. J. Am. Vet. Med. Assoc. 175:1250-1253.

Borges J.R.J., Cunha P.H.J., Moscardini A.R.C., Tortelly R., Franco G.L. \& Silva L.A.F. 2007. Compactação de abomaso em bovinos leiteiros: descrição de cinco casos. Ciênc. Anim. Bras. 8(4):859-864.

Brown C.C., Baker D.C. \& Barker I.K. 2007. Alimentary system, p.1-296. In: Maxie, M.G. (Ed), Jubb, Kennedy and Palmer's Pathology of Domestic Animals. Vol.2. $5^{\text {th }}$ ed. Elsevier, Oxford. 
Câmara A.C.L., Afonso J.A.B., Costa N.A., Mendonça C.L. \& Souza M.I. 2009. Compactação primária do abomaso em 14 bovinos no Estado de Pernambuco. Pesq. Vet. Bras. 29(5):387-394.

Castiglioni V.B.R., Balla A., Castro C. \& Silveira J.M. 1997. Fases de desenvolvimento da planta girassol. Embrapa, Londrina, PR. 24p.

Evangelista A.R. \& Lima J.A. 2001. Utilização de silagem de girassol na alimentação animal. Anais do Simpósio Sobre Produção e Utilização de Forragens Conservadas, Maringá, PR, p.177-217.

Gelberg H.B. 2009. Sistema digestório, p.301-391. In: McGavin M.D. \& Zachary J.F. (Eds), Bases da Patologia em Veterinária. 4ํa ed. Elsevier, Rio de Janeiro.

Guard C. 2006. Impactação abomasal, p.763-765. In Smith B.P. (Ed.), Tratado de Medicina Interna de Grandes Animais. 3a ed. Manole, São Paulo.

Jayme D.G., Gonçalves L.C., Rodrigues J.A.S., Pires D.A.A., Guimarães Júnior R., Rodriguez N.M., Borges I., Borges A.L.C.C., Saliba E.O.S. \& Jayme C.G. 2007. Qualidade das silagens de genótipos de girassol (Helianthus annus) confeiteiros e produtores de óleo. Arq. Bras. Med. Vet. Zootec. 59(5):1287-1293.

Melendez P., Krueger T., Benzaquen M. \& Risco C. 2007. An outbreak of sand impaction in postpartum dairy cows. Can. Vet. J. 48:1067-1070.

Mello R., Nörnberg J.L. \& Rocha M.G. 2004. Potencial produtivo e qualitativo de híbridos de milho, sorgo e girassol ensilagem. Revta Bras. Agrociência 10(1):87-95.

Mello R., Nörnberg J.L., Queiroz A.C., Miranda E.N., Magalhães A.L.R., David D.B. \& Sarmento J.L.R. 2006. Composição química, digestibilidade e cinética de degradação ruminal das silagens de híbridos de girassol em diferentes épocas de semeadura. Revta Bras. Zootec. 35(4):15231534.

Merritt A.M. \& Boucher W.B. 1967. Surgical treatment of abomasal impaction in the cow. Am. Vet. Med. Assoc. 150(10):1115-1120.

McDonald P., Henderson A.R. \& Heron S. 1991. The Biochemistry of Silage. $2^{\mathrm{a}}$ ed. Chalcombe Publications, Marlow, Bucks, UK. 340p.
Mitchell K. 1991. Dietary abomasal impaction in a herd of dairy replacement heifers. J. Am. Vet. Med. Assoc. 198(8):1408-1409.

Moscardini A.R.C. \& Borges J.R.J. 2007. Compactação de abomaso, p.352355. In: Riet-Correa F., Schild A.L., Lemos R.A.A. \& Borges J.R.J. (Eds), Doenças de Ruminantes e Equídeos. Vol. 2. 3aㅗ ed. Gráfica e Editora Palloti, Santa Maria, RS.

Possenti R.A., Junior E.F., Bueno M.S., Bianchini D., Leinz F.F. \& Rodrigues C.F. 2005. Parâmetros bromatológicos e fermentativos das silagens de milho e girassol. Ciência Rural 35(5):1185-1189.

Radostits O.M., Gay C.C., Hinchcliff K.W. \& Constable P.D. 2007. Veterinary Medicine: A textbook of the disease of cattle, horses, sheep, pigs and goats. $10^{\text {th }}$ ed. W.B. Saunders, Edinburgh. 2156p.

Saenz E.A.C. 2005. Modelagem da redução do tamanho de partículas na alimentação de ruminantes. Ciênc. Agrotéc. 29(4):886-893.

Simkins K.M. \& Nagele M.J. 1997. Omasal and abomasal impaction in beef suckler cows. Vet. Rec. 141:466-468.

Souza B.P.S., Coelho S.G., Gonçalves L.C., Vieira F.A.P., Borges A.L.C.C., Rodriguez N.M., Rodrigues J.A.S., Borges I. \& Saliba E.S. 2005. Composição bromatológica da silagem de quatro genótipos de girassol, ensilados em cinco diferentes idades de corte. Arq. Bras. Med. Vet. Zootec. 57 (Supl.2):204-211.

Tomich T.R., Rodrigues J.A.S., Gonçalves L.C., Tomich R.G.P. \& Carvalho A.U. 2003. Potencial forrageiro de cultivares de girassol produzidos na safrinha para ensilagem. Arq. Bras. Med. Vet. Zootec. 55(6):756-762.

Tomich T.R., Pereira L.G.R. \& Gonçalves L.C. 2004a. Alimentos volumosos para o período seco. I. Silagem de girassol. Embrapa Pantanal, Corumbá, MS. 30p.

Tomich T.R., Gonçalves L.C., Tomich R.G.P., Rodrigues J.A.S., Borges I. \& Rodriguez N.M. 2004b. Características químicas e digestibilidade in vitro de silagens de girassol. Revta Bras. Zootec. 33(6) (Supl.1):1672-1682.

Wittek T., Constable P.D. \& Morin D.E. 2005. Abomasal impaction in Holstein-Friesian cows: 80 cases (1980-2003). J. Am. Vet. Med. Assoc. 227(2): 287-291. 